\title{
Prevalence and Antibiotic Susceptibility of Salmonella enterica isolated from Cow Milk, Milk Products and Hands of Sellers in the Tamale Metropolis of Ghana
}

\author{
*1,2 ADZITEY, F; ${ }^{2}$ ASIAMAH, P; ${ }^{3}$ BOATENG, EF \\ ${ }^{1}$ Department of Veterinary Science, ${ }^{2}$ Department of Animal Science, Faculty of Agriculture, University for Development studies, P.O. Box \\ TL 1882, Tamale, Ghana, ${ }^{3}$ College of Food Science and Technology, Nanjing Agricultural University, No. 1 Weigang, 210095, Nanjing, \\ China P.R \\ *Corresponding Author: Email: adzitey@yahoo.co.uk; Tel: +233249995310
}

\begin{abstract}
Salmonella enterica are among the foodborne pathogens of importance due to their involvement in a number of foodborne outbreaks, illnesses and occasionally death. This study was carried out in the Tamale metropolis of Ghana to investigate the prevalence and antibiotic resistance of Salmonella enterica in cow milk, cow milk products and hands of cow milk sellers. The conventional method and the disc diffusion method were used for the isolation and antibiotic resistance of Salmonella enterica, respectively. The overall prevalence of Salmonella enterica was $7.3 \%$ (22/300). Salmonella enterica were detected in $24.0 \%$ (12/50) of raw 'wagashie', $8.0 \%(4 / 50)$ of fried 'wagashie', $6.0 \%$ $(3 / 50)$ of cow milk, $4.0 \%(2 / 50)$ of left hand swab of milk sellers, and $2.0 \%(1 / 50)$ of right hand swab of milk sellers. Salmonella enterica was not isolated from 'brukina'. The prevalence of Salmonella enterica did not differ $(\mathrm{P}=0.193)$ among fried 'wagashie', cow milk, hand swab of milk sellers and 'brukina' samples. However, the prevalence of Salmonella enterica in raw 'wagashie' was significantly higher $(\mathrm{P}=0.000)$ than the other samples examined. Resistant to erythromycin $(86.0 \%)$ was most frequently detected. The Salmonella enterica isolates were highly susceptible to ciprofloxacin $(100.0 \%)$, chloramphenicol $(91.0 \%)$, ceftriaxone $(91.0 \%)$, sulphamethoxazole/trimethoprim $(91.0 \%)$, tetracycline (86.0\%) and ampicillin (86.0\%). Of the 22 Salmonella enterica isolates, 14 were resistant to only one antibiotic, 4 were resistant to two antibiotics and 2 were resistant to three antibiotics. Two Salmonella enterica isolates were resistant to none of the antibiotics. This study revealed that some milk products and other samples were contaminated with Salmonella enterica. The isolated Salmonella enterica were susceptible to most of the antibiotics examined but were highly resistant to erythromycin.
\end{abstract}

\section{DOI: $\underline{\text { https://dx.doi.org/10.4314/jasem.v24i1.8 }}$}

Copyright: Copyright (C) 2020 Adzitey et al. This is an open access article distributed under the Creative Commons Attribution License (CCL), which permits unrestricted use, distribution, and reproduction in any medium, provided the original work is properly cited.

Dates: Received: 30 November 2019; Revised: 20 December 2019; Accepted: 23 December 2019

Keywords: Antimicrobials, Foodborne pathogens, Food safety, Milk, Milk products

Milk and milk products constitute important nutritional components of human diets and play prominent roles in human nutrition (Medhammar et al., 2012). Bacterial contamination of milk and its products can occur from within the udder, outside the udder and from milk handling equipment (Oliver et al., 2005; Adzitey et al., 2018). Cow health, milking procedures, equipment sanitation and environment such as water and personnel can influence the level of microbial contamination of raw milk (Altug and Bayrak, 2003; Adzitey et al., 2016a). There have been outbreaks of milk-borne diseases in humans, with pathogens such as Salmonella spp., S. aureus, E. coli, and Yersinia spp. being implicated (Yagoub et al., 2005).

Salmonella is a rod-shaped, Gram-negative, non-spore forming, catalase positive, oxidase negative and predominantly motile bacteria possessing peritrichous flagella (Yan et al., 2003). Its members are generally small enterobacteria with a diameter ranging from
$0.7 \mu \mathrm{m}$ to $1.5 \mu \mathrm{m}$ and a length of $2.0 \mu \mathrm{m}$ to $5.0 \mu \mathrm{m}$ (Yan et al., 2003). Salmonella grows optimally at a temperature of 35 to $37^{\circ} \mathrm{C}, \mathrm{pH}$ of 6.5 to 7.5 and water activity of 0.84 of 0.94 (Yan et al., 2003). Salmonella is one of the main causes of foodborne illnesses in developing as well as in developed countries (Adams and Moss, 2008; Scallan et al., 2011). Salmonella causes gastrointestinal infections that are accompanied by inflammation of intestinal epithelia, diarrhea and vomiting (Hensel, 2004). Because Salmonella is shed in the animal's faeces, there is a risk of the pathogens contaminating milk and milk products.

Outbreaks of milk-borne diseases have occurred despite pasteurization caused either by improper pasteurization or recontamination thereby posing some risks to consumers (DeSilva et al., 2001). Milk and milk products can be contaminated with pathogens that are resistant to several antibiotics. Hleba et al. (2015) reported that it is currently impossible to effectively exclude antibiotic resistant strains from 
milk products. Thus, exposure of milk to antibiotics is one of the pathways for transfer of antibiotic resistant pathogens to humans. Yet, data on the prevalence and antibiotic susceptibility of Salmonella in milk and milk products in Ghana are inadequate. To be able to create more awareness of Salmonella infections in the country, there is the need to undertake studies on prevalence and antibiotic susceptibility of Salmonella enterica in foods for human consumption.

\section{MATERIALS AND METHODS}

Study area: This study was conducted in the Tamale metropolis. Tamale is the capital town of the Northern region of Ghana. The Metropolis has a total estimated land size of 646.90180sqkm (Ghana Statistical Service (GSS), 2010). Geographically, the city lies between latitude $9^{\circ} 16$ and $9^{\circ} 34$ North and longitudes $0^{\circ} 36$ and $0^{\circ} 57$ West (GSS, 2010). It has a population of about $2,479,461$ and a growth rate of $2.9 \%$ (GSS, 2010). Tamale has annual rainfall of $1100 \mathrm{~mm}$ and mean temperature range of $28^{\circ} \mathrm{C}$ to $43^{\circ} \mathrm{C}(\mathrm{GSS}, 2010)$.

Samples examined: Three hundred milk, milk products and hands of milk/milk product sellers were randomly sampled in the Tamale metropolis. The samples included; cow milk, raw 'wagashie', fried 'wagashie', 'brukina', and palm swabs of the hands of milk sellers. 'Wagashie' is a traditional West African cottage cheese normally produced by the semi-nomadic Fulani. 'Brukina' or 'Fura' is a milk product made mainly from millet that has undergone fermentation. 'Wagashie' and 'brukina' are delicacies for many Ghanaians. Fifty samples of each item were collected. They were analysed for the presence of Salmonella enterica. Isolated Salmonella enterica were subjected to antimicrobial susceptibility test to determine their resistances.

Isolation and identification of Salmonella enterica: Salmonella enterica were isolated and identified according to the procedures in the Bacteriological Analytical Manuel of USA-FDA (Andrews et al., 2015). Briefly, samples were pre-enriched in buffered peptone water (BPW) and incubated at $37^{\circ} \mathrm{C}$ for 18 24hours. These were the ratios for the samples; $10 \mathrm{ml}$ of milk sample: $90 \mathrm{ml}$ of BPW, $10 \mathrm{~g}$ of 'wagashie' (fried and raw): $90 \mathrm{ml}$ of BPW, $10 \mathrm{ml}$ of 'brukina': $90 \mathrm{ml}$ of BPW, and 1 swab of hand (left and right, $\left.10 \mathrm{~cm}^{2}\right): 10 \mathrm{ml}$ of BPW. After pre-enrichment, $0.1 \mathrm{ml}$ portion was transferred to $10 \mathrm{ml}$ Rappaport Vassilidis (RV) broth and $1 \mathrm{ml}$ portion into $9 \mathrm{ml}$ selenite cysteine (SC) broth and incubated at $42^{\circ} \mathrm{C}$ and $37^{\circ} \mathrm{C}$, respectively for 24-48hours. Enriched samples were streaked on xylose lysine deoxycholate (XLD) and Brilliant Green Agar (BGA) with an inoculating loop. The plates (XLD and BGA) were incubated at $37^{\circ} \mathrm{C}$ for
24 to 48 hours. Presumptive Salmonella colonies were picked and purified on tryptic soy agar. Confirmation and identification was carried out using Gram stain, triple sugar iron agar (TSI), lysine iron agar (LIA) and Salmonella latex agglutination test kits. All media and kits used were purchased from Oxoid, UK.

Antimicrobial susceptibility test: The disk diffusion method was used to determine the antibiotic susceptibility of 22 Salmonella enterica isolates against 8 antimicrobial agents (ampicillin (Amp) 30 $\mu \mathrm{g}$, chloramphenicol (C) $30 \mu \mathrm{g}$, ciprofloxacin (Cip) $5 \mu \mathrm{g}$, ceftriaxone (Cro) $30 \mu \mathrm{g}$, gentamicin (Cn) $10 \mu \mathrm{g}$, erythromycin (E) $15 \mu \mathrm{g}$, suphamethoxazole/trimethoprim (Sxt) $22 \mu \mathrm{g}$ and tetracycline (Te) $30 \mu \mathrm{g}$, all purchased from Oxoid, UK).

Pure Salmonella enterica isolates were grown in tryptic soy broth (TSB) (Oxoid, UK) at $37^{\circ} \mathrm{C}$ for 16 to 24 hours and the concentration adjusted using sterile TSB until 0.5 McFarland turbidity was attained. Approximately, one hundred microliters of the culture were spread plated on Mueller Hinton agar (Oxoid, UK). The antibiotic disks were placed on the surface of the agar plate at a distance to avoid overlapping of inhibition zones. The plates were incubated at $37^{\circ} \mathrm{C}$ for 16 to 24 hours and the results were interpreted as resistance, susceptibility and intermediate according to the Clinical and Laboratory Standards Institution guidelines (Clinical and Laboratory Standards Institute (CLSI), 2008).

Statistical analysis: The data obtained was analyzed using binary logistic of IBM Statistical Package for the Social Sciences (SPSS) Version 17. Test for statistical difference was done using wald chi-square at 5\% significance level.

\section{RESULTS AND DISCUSSION}

Prevalence of Salmonella in cow milk, cow milk products and hand samples: The distribution of the Salmonella enterica in the cow milk, 'wagashie' (raw and fried), hand of cow milk sellers (left and right hands) and 'brukina' samples analyzed in the Tamale metropolis of Ghana is showed in Table 1. Out of the 300 samples examined, 22 (7.3\%) were positive for Salmonella enterica. The prevalence of Salmonella enterica was $24.0 \%$ (12/50), 8.0\% (4/50), 6.0\% (3/50), $4.0 \%(2 / 50), 2.0 \%(1 / 50)$ and $0.0 \%(0 / 50)$ for raw 'wagashie', fried 'wagashie', cow milk, left hand swab of milk sellers, right hand swab of milk sellers and 'brukina', respectively. The prevalence of Salmonella in raw 'wagashie' was significantly higher $(\mathrm{P}=0.000)$ than the rests of the samples examined. There was no significant difference $(\mathrm{P}=0.193)$ in the prevalence of 
Salmonella enterica between fried 'wagashie', cow milk, hand swab of milk sellers and 'brukina'. This study examined the prevalence and antibiotic resistance of Salmonella in cow milk, cow milk products and hand samples of cow milk sellers. The overall prevalence of Salmonella enterica in the milk and its related samples was 7.3\%. Raw 'wagashie' was the most contaminated source, followed by fried 'wagashie', cow milk, left hand and right hand. Salmonella enterica were not detected in 'brukina'. The presence of Salmonella in the raw 'wagashie' was significantly higher $(\mathrm{P}=0.000)$ than the rest of the samples examined.

Table 1: Distribution of Salmonella enterica in milk and its related samples

\begin{tabular}{llll}
\hline Type of sample & $\begin{array}{l}\text { Number of } \\
\text { samples tested }\end{array}$ & $\begin{array}{l}\text { Number of samples } \\
\text { positive/negative }\end{array}$ & $\begin{array}{l}\text { Percentage } \\
\text { prevalence }\end{array}$ \\
\hline Raw 'wagashie' & 50 & 12 & 24.0 \\
Fried 'wagashie' & 50 & 4 & 8.0 \\
Cow milk & 50 & 3 & 6.0 \\
Left hand & 50 & 2 & 4.0 \\
Right hand & 50 & 1 & 2.0 \\
'Burkina' & 50 & 0 & 0.0 \\
Total & 300 & 22 & 7.3 \\
\hline
\end{tabular}

Contamination of raw 'wagashie' (24.0\%) by Salmonella enterica was also statistically higher $(\mathrm{P}=$ $0.000)$ than fried 'wagashie' $(8.0 \%)$; thus frying 'wagashie' likely reduced the level of Salmonella contamination. Also cow milk $(6.0 \%)$, which are normally pasteurized for sale at the Tamale metropolis involved the use of heat during processing, and had lower contamination rate as compared to raw 'wagashie'. Lower contamination of hand samples by Salmonella enterica suggests that the hands are not the primary source of this foodborne pathogen but might have been cross contaminated. Hands of the sellers can also cause cross contamination of different milk products sold in this metropolis. The absence of Salmonella enterica in 'brukina' may be attributed to the cold temperature (about $4^{\circ} \mathrm{C}$ ) they are kept for sale. Mhone et al. (2012) examined 120 raw cow milk and 20 processed cow milk from smallholder dairy farms in Zimbabwe and found no Salmonella enterica. Similarly, to this study, Salmonella enterica were not found in 'brukina' but were found in the other samples examined. Karns et al. (2005) also examined 854 bulk tank milk from dairies across the United States and found that $100(11.7 \%)$ and $22(2.6 \%)$ were positive for Salmonella enterica by real time PCR assay and the conventional culture techniques, respectively. In Addis Ababa, 2.1\% (2/91) of cow milk samples were contaminated with Salmonella enterica (Tesfaw et al., 2013). This study found an average prevalence of $7.3 \%$. A number of factors including the study area, isolation method, number and type of samples examined and the overall hygienic conditions employed in the handling of milk and its related samples contribute to differences in the prevalence rate.

Milk and milk products in the Tamale Metropolis are normally processed without adherence to strict hygienic practices and are sold locally (Adzitey et al.,
2018). The contamination of the pasteurized milk, milk products and hands by Salmonella enterica attests to the fact that strict hygienic practices were not followed in their preparation. The possible sources of Salmonella enterica contamination may be at the farm, during processing and/or selling points. It was observed that farmers/milkers use ordinary or unboiled water without detergents to wash equipment, udder and their hands before and after milking at the farms milk samples were collected. Also milking was done on some lactating cows that were dirty. Bonfoh et al. (2003) reported that well-constructed herd structure, milking and pre-storage conditions are important determinants of the quality and safety of raw milk. It was also observed in this study that majority of the milk sellers in the market operated very close to main streets without shades exposing the milk and milk products to dust and other contaminants. Unhygienic practices observed among some of the milk sellers included wearing unclean clothes, allowing other people to sell milk to consumers, use of dirty/uncleaned hands to sell and drinking from cups used to sell milk. These practices coupled with the environment under which milk and milk products are sold are potential sources of contamination. The presence of Salmonella enterica in the milk, milk products and hands of milk sellers is very disturbing since majority of people in the northern region and the country as a whole consume these products.

Table 2. Percent Salmonella enterica isolates from cow milk, and other samples that are resistant to different antibiotics

\begin{tabular}{|c|c|c|c|}
\hline \multirow[b]{2}{*}{ Antimicrobial } & \multicolumn{3}{|c|}{$\begin{array}{l}\text { Dis tribution of antibiotic } \\
\text { resis tance in Sialmónella spop }\end{array}$} \\
\hline & $R(\%)$ & $I(\%)$ & $s(\%)$ \\
\hline Ampicillin (Amp) $30 \mu \mathrm{g}$ & 9.0 & 5.0 & 86.0 \\
\hline phenicol (C) $30 \mu$ g & 5.0 & 5.0 & 91.0 \\
\hline Ciprofloxacin (Cip) $5 \mu \mathrm{g}$ & 0.0 & 0.0 & 100.0 \\
\hline Ceftriaxone (Cro) $30 \mu \mathrm{g}$ & & 9.0 & 91.0 \\
\hline Gentamicin (Cn) $10 \mu \mathrm{g}$ & 14.0 & 18.0 & 68.0 \\
\hline Erythromycin (E) $15 \mu \mathrm{g}$ & 86.0 & 9.0 & 5.0 \\
\hline Sxt $22 \mu \mathrm{g}$ & 0.0 & 9.0 & 91.0 \\
\hline Tetracycline $(\mathrm{Te}) 30 \mathrm{\mu g}$ & 14.0 & 0.0 & 86.0 \\
\hline
\end{tabular}

Key: $\mathrm{R}=$ resistant, $\mathrm{I}=$ intermediate resistant, $\mathrm{S}=$ susceptibility, $\mathrm{Sxt}=$ Suphamethoxazole/trimethoprim 
Salmonella is known to cause Salmonellosis with symptoms such as nausea, vomiting and diarrhea (Adams and Moss, 2008). Additionally, complications associated with Salmonellosis include septicemia, reactive arthritis and even death (Adams and Moss, 2008; Scallan et al., 2011).

Antibiotic susceptibility of Salmonella isolated from cow milk, cow milk products and hand samples: The antibiotic resistance of the Salmonella enterica is presented in Table 2. A high percentage (86.0\%) of the Salmonella enterica were resistant to erythromycin. Susceptibility to ciprofloxacin $(100.0 \%)$, ceftriaxone (91.0\%), chloramphenicol (91.0\%), sulphamethoxazole/trimethoprim $\quad(91.0 \%)$, tetracycline $(86.0 \%)$ and ampicillin $(86.0 \%)$ was also high. The 22 Salmonella enterica isolates exhibited minor intermediate resistances to all the antibiotics except ciprofloxacin and tetracycline. The antibiotic resistance pattern revealed that 14 isolates were resistant to only one antibiotic, 4 isolates were resistant to two antibiotics and 2 isolates were resistant to three antibiotics (Table 3). Two Salmonella enterica isolates were resistant to none of the antibiotics. Resistant to only erythromycin was most common.

Table 3: Contaminated samples with Salmonella enterica and corresponding antimicrobial resistance

\begin{tabular}{|c|c|c|c|}
\hline No. & Sample & $\begin{array}{l}\text { Antibiotic } \\
\text { resistant } \\
\text { pattern }\end{array}$ & $\begin{array}{l}\text { Number of } \\
\text { antibiotics }\end{array}$ \\
\hline 1 & Raw 'wagashie' & - & 0 \\
\hline 2 & Fried 'wagashie' & - & 0 \\
\hline 3 & Left hand & $\mathrm{E}$ & 1 \\
\hline 4 & Left hand & $\mathrm{E}$ & 1 \\
\hline 5 & Right hand & $\mathrm{E}$ & 1 \\
\hline 6 & Raw 'wagashie' & $\mathrm{E}$ & 1 \\
\hline 7 & Raw 'wagashie' & $\mathrm{E}$ & 1 \\
\hline 8 & Raw 'wagashie' & $\mathrm{E}$ & 1 \\
\hline 9 & Fried 'wagashie' & $\mathrm{E}$ & 1 \\
\hline 10 & Fried 'wagashie' & $\mathrm{E}$ & 1 \\
\hline 11 & Fried 'wagashie' & $\mathrm{E}$ & 1 \\
\hline 12 & Fried 'wagashie' & $\mathrm{E}$ & 1 \\
\hline 13 & Fried 'wagashie' & $\mathrm{E}$ & 1 \\
\hline 14 & Fried 'wagashie' & $\mathrm{E}$ & 1 \\
\hline 15 & Fried 'wagashie' & $\mathrm{E}$ & 1 \\
\hline 16 & Fried 'wagashie' & $\mathrm{E}$ & 1 \\
\hline 17 & Cow milk & $\mathrm{CTe}$ & 2 \\
\hline 18 & Cow milk & ETe & 2 \\
\hline 19 & Fried 'wagashie' & $\mathrm{ECn}$ & 2 \\
\hline 20 & Fried 'wagashie' & $\mathrm{ECn}$ & 2 \\
\hline 21 & Cow milk & EAmpTe & 3 \\
\hline 22 & Fried 'wagashie' & EAmpCn & 3 \\
\hline
\end{tabular}

Antibiotics are widely used for the treatment of bacterial infections. Although their use has received much attention and cautions, their use for therapeutic and other purposes cannot be totally eliminated (Adzitey, 2015). In this study, most of the Salmonella enterica isolates of milk, milk product and seller's hands were susceptible to the 8 different antibiotics examined; some of the isolates were resistant and others exhibited intermediate resistant. All the Salmonella enterica isolates were susceptible to quinolones (ciprofloxacin). Similarly, Tesfaw et al. (2013) found that all Salmonella enterica isolates from milk and milk products were susceptible to ciprofloxacin. Susceptibility $\geq 68.0 \%$ occurred for aminoglycosides (gentamycin), penicillins (ampicillin), tetracycline, chloramphenicol, cephalosporins (ceftriaxone) and sulfonamides (suphamethoxazole/trimethoprim). Intermediate resistant occurred for all the antibiotics except ciprofloxacin and tetracycline. Salmonella enterica isolates that exhibited intermediate resistances have the tendency to become resistant (Adzitey et al., 2015). Resistant to macrolides (erythromycin) was high in the current study. Tesfaw et al. (2013) reported that $83.3 \%, 50.0 \%$, and $16.7 \%$ of milk and milk product Salmonella enterica isolates were resistant to tetracycline, ampicillin, and chloramphenicol, respectively. Salmonella enterica isolates from cow milk were resistant to ampicillin (100\%), tetracycline $(50 \%)$, gentamycin $(33.3 \%)$, and chloramphenicol $16.7 \%$ (Addis et al., 2011). In this current study, lower resistances $(5.00 \%$ to $14.0 \%)$ to these antibiotics (tetracycline, ampicillin, gentamycin and chloramphenicol) were observed.

Of the 22 Salmonella enterica isolates, 4 were resistant to two antibiotics, 2 were resistant to three antibiotics, 14 were resistant to one antibiotic and 2 were resistant to none of the antibiotics. Thus $9.09 \%(2 / 22)$ of the Salmonella enterica isolates were multidrug resistant.

The 2 Salmonella enterica isolates that were multidrug resistance exhibited resistant patterns; EAmpTe (erythromycin-ampicillin-tetracycline) and $\mathrm{EAmpCn}$ (erythromycin-ampicillin-gentamicin). The resistant patterns $\mathrm{CTe}$ (chloramphenicol-tetracycline), ETe (erythromycin-tetracycline) and ECn (erythromycingentamicin) were exhibited by an isolate each. Multidrug resistant isolates are dangerous and difficult to control when they are involved in infection compared to non-multidrug resistant isolates and Salmonella enterica isolates resistant to more than one antibiotic have been reported by other investigators (Foley and Lynne, 2008; Tesfaw et al., 2013; Abike et al., 2015; Adzitey et al., 2016b; Raja and Adzitey, 2017). Tesfaw et al. (2013) found that milk and milk product Salmonella enterica isolates were resistant to TeAmp (tetracycline-ampicillin) and TeAmpAmo (tetracycline-ampicillin-amoxicillin).

They also reported that $50.0 \%$ of the Salmonella enterica isolates were multiple antibiotic resistant 
while the rest were resistant to a single antibiotic. The reasons for the development of resistance among foodborne pathogens including Salmonella enterica have been linked to the indiscriminate use of antibiotics for therapeutic and growth purposes in animals (Forshell and Wierup, 2006).

Conclusions: The present study revealed that some milk and milk products were contaminated with Salmonella enterica. Raw 'wagashie' was the most contaminated source, followed by fried 'wagashie', cow milk, left hand and right hand. Salmonella enterica was not found in 'burkina'. Resistance of Salmonella enterica to some of the antimicrobial drugs except ciprofloxacin may be attributed to the use of these antimicrobials for therapeutic purposes in cattle production in the Tamale metropolis.

\section{REFERENCES}

Abike, TO; Olufunke, OA; Oriade, KD (2015). Prevalence of multiple antibiotic resistant Escherichia coli serotypes in cow raw milk samples and traditional dairy products in Osun State, Nigeria. British Microbiology Research Journal, 5: 117-125.

Adams, R; Moss, MO (2008). Food microbiology. RSC Publishing. Cambridge, UK. Pp 1-436.

Addis, Z; Kebede, N; Sisay, Z; Alemayehu, H; Wubetie, A; Kassa, T (2011). Prevalence and antimicrobial resistance of Salmonella isolated from lactating cows and in contact humans in dairy farms of Addis Ababa: a cross sectional study. BMC Infectious Diseases, 11: 222.

Adzitey, F; Amposah, CA; Teye, GA (2018). Prevalence and antimicrobial resistance patterns of $E$. coli isolates from cow milk, milk products and handlers in the Tamale Metropolis of Ghana. Nigerian Veterinary Journal, 39:338-345.

Adzitey, F; Saba, CKS; Teye, GA (2016a). Antibiotic susceptibility of $E$. coli isolated from milk and hands of milkers in Nyankpala community of Ghana. Current Research in Dairy Sciences, 8: 611.

Adzitey, F; Ashiagbor, CNK; Abu, H (2016b). Prevalence and antibiotic susceptibility of Salmonella spp. from water sources in Tamale, Ghana. International Journal of One Health, 2: 24-28.
Adzitey, F; Nsoah, JK; Teye, G. (2015). Prevalence and antibiotic susceptibility of Salmonella enterica isolated from beef and its related samples in Techiman Municipality of Ghana. Turkish Journal of Agriculture - Food Science and Technology, 3: 644-650.

Adzitey, F (2015). Antibiotic classes and antibiotic susceptibility of bacterial isolates from selected poultry; a mini review. World's Veterinary Journal, 5: 36-41.

Altug, G; Bayrak, Y (2003). Microbiological analysis of caviar from Russia and Iran. Food Microbiology, 2: 83-86.

Andrews, WH; Wang, H; Jacobson, A; Hammack, T (2015). Bacteriological Analytical Manual, Chapter 5, Salmonella. Available at: https://www.fda.gov/Food/FoodScienceResearch /Laboratory Methods/ucm070149.htm.

Bonfoh, B; Wasem, A; Traore, AN; Fane, A; Spillmann, H; Simbe, CF; Alfaroukh, IO; Nicolet, J; Farah, Z; Zinsstag, J (2003). Bacterial quality of cows' milk taken at different intervals from the udder to the selling point in Bamako (Mali). Food Control, 14: 495-500.

Clinical \& Laboratory Standards Institute. Standards for antimicrobial susceptibility testing; Eighteenth informational supplement. Wayne, P.A. M100-S18 (MS); 2008.

DeSilva, ZN; Cunha, AS; Lins, MC; Carneiro, L; Almeida, AC; Queuro, ML (2001). Isolation and serological identification of enteropathogenic Escherichia coli in pasteurized milk in Brazil. Revista de Saude publica, 35:375-379.

Foley, SL; Lynne, AM (2008). Food animalassociated Salmonella challenges: Pathogenicity and antimicrobial resistance. Journal of Animal Science, 86: E173-E187.

Forshell, LP; Wierup, M (2006). Salmonella contamination: a significant challenge to the global marketing of animal food products. Revue Scientifique et Technique - Office International Des Epizooties, 25: 541-554.

Ghana Statistical Service (2010). Population and Housing Census. Available at: http://www2.statsghana.gov.gh/docfiles/2010_Di strict_Report/Northern/Tamale\%20Metropolitan. pdf. 
Hensel, M (2004). Review; Evolution of pathogenicity islands of Salmonella enterica. International Journal of Medical Microbiology, 294: 95-102.

Hleba, L; Petrová, J; Kántor, A; Čuboň, J; Kačániová, M (2015). Antibiotic resistance in Enterobacteriaceae strains isolated from chicken and milk samples. J. Microbiology, Biotechnology and Food Sciences, 4:19-22.

Karns, JS; Van Kessel, JS; McCluskey, BJ; Perdue, ML (2005). Prevalence of Salmonella enterica in bulk tank milk from US dairies as determined by polymerase chain reaction. Journal of Dairy Science, 88: 3475-3479.

Medhammar, E; Wijesinha-Bettoni, R; Stadlmayr, B; Nilsson, E; Charrondiere, UR; Burlingame, B (2012). Composition of milk from minor dairy animals and buffalo breeds: a biodiversity perspective. J. Sci. Food. Agric. 2: 445-474.

Mhone, TA; Matope, G; Saidi, PT (2012). Detection of Salmonella spp., Candida albicans, Aspergillus spp., and antimicrobial residues in raw and processed cow milk from selected small holder farms of Zimbabwe. Veterinary Medicine International, doi:10.1155/2012/301902.

Oliver, SP; Jayarao, BM; Almeida, RA (2005). Foodborne pathogens in milk and the dairy farm environment: food safety and public health implications. Foodborne Pathogens and diseases, 2:115-129.
Raja, AND; Adzitey, F (2017). Prevalence and antibiotic resistance of Salmonella serovars isolated from spent hens and its environmental samples in Penang and Kedah, Malaysia. Journal Tropical Agriculture and Food Science, 45: 3750.

Scallan, E; Hoekstra, RM; Angulo, FJ; Tauxe, RV; Widdowson, MA; Roy, SL; Jones, JL; Griffin, PM (2011). Foodborne illness acquired in the United States-major pathogens. Emerging Infectious Diseases, 17: 7-15.

Tesfaw, L; Biruhalem, T; Sefinew, A; Haile, A; Zufan, S; Haileleul, N (2013). Prevalence and antimicrobial resistance profile of Salmonella enterica isolates from dairy products in Addis Ababa, Ethiopia. African Journal of Microbiology Research, 7: 5046-5050.

Yagoub, SO; Awadlla, NE; El Zubeir, IEM (2005). Incidence of some potential pathogens in raw milk in Khartoum North (Sudan) and their susceptibility to antimicrobial agents. Journal of Animal and Veterinary Advances, 4: 341-344.

Yan, SS; Pandrak, ML; Abela-Rider, B; Punderson, JW; Fedorko, DP; Foley, SL (2003). An overview of Salmonella typing public health perspectives. Clinical and Applied Immunology Reviews, 4: 189-204. 